Org Lett. 2016 August 19; 18(16): 3976-3979. doi:10.1021/acs.orglett.6b01742.

\title{
Mechanistically Inspired Route toward Hexahydro-2H-chromenes via Consecutive [4 + 2] Cycloadditions
}

\author{
Kumar Dilip Ashtekar ${ }^{\dagger}$, Xinliang Ding $^{\dagger}$, Edmond Toma, Wei Sheng, Hadi Gholami, \\ Christopher Rahn, Paul Reed, and Babak Borhan * \\ Department of Chemistry, Michigan State University, East Lansing, Michigan 48824, United \\ States
}

\begin{abstract}
Utilizing two robust $\mathrm{C}-\mathrm{C}$ bond-forming reactions, the Baylis-Hillman reaction and the DielsAlder reaction, we report a highly enantio-, regio-, and diastereoselective synthesis of hexahydro- $2 H$-chromenes via two sequential $[4+2]$ cycloadditions. These tandem and formal cycloadditions have also been performed as a "one-pot" sequence to access the corresponding heterocycles constituting up to five contiguous stereocenters in excellent yields and stereoselectivity.
\end{abstract}

\section{Graphical abstract}

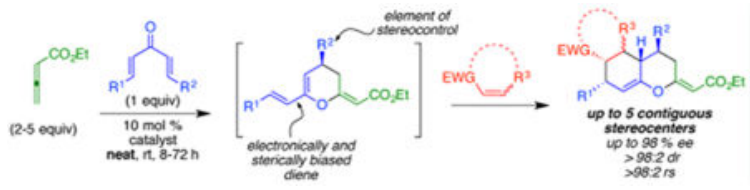

\begin{abstract}
Although the synthesis of hexahydro- $2 H$-chromenes (4) can be achieved through a number of strategic disconnections, ${ }^{1}$ we sought to explore a rapid assembly, as depicted retrosynthetically in Scheme 1. The enantioenriched precursor diene (3), required for the concomitant Diels-Alder reaction, would be obtained via a chiral amine catalyzed modified Baylis-Hillman reactionof allenoate $\mathbf{2}$ with chalcone 1 that precedes a formal [4+2] cycloaddition. The latter strategy provides an expedient route toward substituted hexahydro- $2 H$-chromenes with high stereo-selectivity via two consecutive [4 + 2] cycloaddition reactions.
\end{abstract}

The approach described above requires a facile strategy for the synthesis of dihydropyrans with the general structure depicted in $\mathbf{3}$ in high enantioselectivity. A number of groups, including ours, have addressed this requirement. ${ }^{2}$ Our endeavor in this field commenced with the early discovery for the mechanistically guided synthesis of substituted

\footnotetext{
*Corresponding Author: babak@chemistry.msu.edu.

†uthor Contributions: K.D.A. and X.D. contributed equally.

Supporting Information: The Supporting Information is available free of charge on the ACS Publications website at DOI: 10.1021/ acs.orglett.6b01742.

Notes: The authors declare no competing financial interest.
} 
dihydropyrans. ${ }^{2 \mathrm{e}}$ As shown in Scheme 1, we circumvent the rate-limiting proton transfer associated with the Baylis-Hillman reaction of enones and allenoates (path A, $\mathbf{2 d} \rightarrow \mathbf{2 e}$ ), ${ }^{3}$ by utilizing acyclic enones (1) as secondary electrophiles. The relatively fast intramolecular trapping of the oxyanion $\mathbf{2 f}$ siphons the reaction toward formation of the corresponding dihydropyran $\mathbf{3}$ in high yields and enantioselectivity via path B (modified Baylis-Hillman route $^{4}$ ). We predicted that a similar transformation initiated with a symmetric chalcone (such as $\mathbf{1}$, Scheme 1) would yield the required diene $\mathbf{3}$ for the proposed Diels-Alder reaction. Furthermore, we surmised that the enantioenriched $\mathrm{C} 4$ substituent in $\mathbf{3}$ would serve as a stereochemical driver in the concomitant $[4+2]$ cycloaddition. The conjugated diene motif in 3 displays a unique integration of two key features: (a) the extended cross-conjugation of the pyranyl oxygen atom (O1) results in an electronic bias that may allow regioselective trapping of a unsymmetrically substituted dienophile and (b) the nucleophilic carbon (C5) and the stereochemical driver (C4 substituent), both being part of a conformationally rigid cyclic framework, may allow an easy access to diastereoselective $[4+2]$ cycloadditions. The latter hypotheses were readily examined by subjecting a model substrate, dibenzalacetone 1a, to the catalytic asymmetric formal [4+2] cycloaddition under an optimized set of conditions (Scheme 2). Initial screening with several chiral amines revealed $\mathbf{A}$ and $\mathbf{B}$ as optimum catalysts for the synthesis of oxatriene 3a- $(S)$ and $\mathbf{3 a}-(R)$, respectively. Using catalyst A under solvent-free conditions, oxatriene 3a- $(S)$ was obtained in $98 \%$ yield and $98 \%$ ee. Subsequent treatment of this oxatriene with maleic anhydride $4 \mathbf{a}$ furnished the stereopentad 5aa as a single diastereomer in $78 \%$ yield. This offers an alternate approach to previous explorations ${ }^{5}$ directed toward controlling stereoselectivity in cycloadditions of dienes bearing an allylic chiral center. ${ }^{6}$

Intrigued by the levels of stereoinduction, especially in the latter cycloaddition, we decided to probe the origins of stereoselectivity by employing quantum chemical computational analysis of the transition states (TS) at the B3LYP/6-31G*/SM8 (toluene) level of theory. ${ }^{7}$ Hydroquinidine (instead of catalyst $\mathbf{A}$ ) was employed to reduce the computational expense. In accordance with the previous findings, ${ }^{2 \mathrm{e}}$ the diastereomeric transition state TS-1 (Figure 1a), which provides the product 3a- $(S)$, was favored by $2.7 \mathrm{kcal} / \mathrm{mol}$ (corresponding to er $=$ 99:1). The steric congestion (gauche interactions highlighted by bonds in red color) and the diminished electrostatic stabilization (as determined by the $\mathrm{C}=\mathrm{O}^{\delta-} \ldots{ }^{\delta+}+\mathrm{NR}_{4}$ distance) in TS-2 make it energetically less favorable than TS-1. The computational analysis corroborates the experimental observation in the initial [4+2] cycloaddition $(98 \%$ ee using the hydroquinidine based catalyst-A, see the SI for details). We next examined the stereoinduction associated with the Diels-Alder reaction of $\mathbf{3 a}-(S)$ with maleic anhydride 4a. In agreement with the experimentally observed endo-selectivity, ${ }^{5 \mathrm{e}, 8} \mathrm{TS}-3$ endo was found to be more favored over TS-4 $4_{\text {exo }}$ by $2.8 \mathrm{kcal} / \mathrm{mol}$ (Figure $\left.1 \mathrm{~b}\right)$. TS- $4_{\text {exo }}$ also suffers from the electrostatic repulsion between the $\pi$-cloud of the $\mathrm{C} 4$ phenyl substituent in $\mathbf{3 a}-(S)$ and the electron density on the proximal carbonyl of $\mathbf{4 a}$ (see the SI for details). Furthermore, the corresponding TS-5 endo that involves the approach of dienophile $4 \mathbf{a}$ from the sterically hindered face of the diene is disfavored over TS- 3 endo by $1.8 \mathrm{kcal} / \mathrm{mol}$ (see dashed box in Figure 1b). Although the B3LYP/6-31G* level of theory underestimates the energetics of secondary interactions in the Diels-Alder reaction, ${ }^{9}$ it clearly depicts the correct energetic trend as observed experimentally. ${ }^{10}$ Overall, the stereochemistry at $\mathrm{C} 4$, obtained from the 
Baylis-Hillman reaction, governs the stereospecificity in the concomitant Diels-Alder reaction.

The mechanistic nuances underlying the modified Baylis-Hillman reaction of allenoates (primary electrophile) with dibenzalacetone (secondary electrophile) are more complex than the simplified picture depicted in Scheme 1, leading to the following central question.

Despite the possibility for the formation of several theoretical adducts (based on the relative reactivity of the primary and secondary electrophile), which factor governs the formation of $\mathbf{3}$ as the predominant product? To address this question, the identity of stable intermediates that arise during the reaction of $\mathbf{1 a}$ with $\mathbf{2}$, catalyzed by quinuclidine $\mathbf{C}$ (an achiral surrogate of catalysts $\mathbf{A}$ and $\mathbf{B}$ ), were investigated by ESI-MS (Figure 2). A nucleophilic attack of the Lewis base catalyst $\mathbf{C}$ on allenoate $\mathbf{2}$ generates the zwitterionic intermediate $\mathbf{2} / \mathbf{C}$. The resulting enolate can attack another molecule of $\mathbf{2}$ to furnish the intermediate $\mathbf{2}^{2} / \mathbf{C}$. Sequential additions of $\mathbf{2}$ will yield the trimeric adduct $\mathbf{2}^{3} / \mathrm{C}$ and higher oligomers that constitute several polymeric adducts in equilibrium. This is indeed supported by ESI-MS analysis of a preincubated mixture of $\mathbf{C}$ and $\mathbf{2}$ (Figure $2 b$ ). When this mixture was treated with the secondary electrophile $1 \mathbf{a}$, intermediates $\mathbf{1 a - 2 / C}$ en route to product $\mathbf{3 a}$ and higher order adduct $\mathbf{1 a - 2} / \mathbf{C}$ were observed (Figure $2 \mathrm{c}$ ). ${ }^{11}$ This study suggests that the reaction of $\mathbf{1 a}, \mathbf{2}$, and $\mathbf{C}$ indeed yields a mixture of several adducts in equilibrium; however, the irreversibility associated with the ring-closure step (see dashed box, Figure 2a) adventitiously siphons the equilibrium mixture to the desired cycloadduct $\mathbf{3 a}$.

To explore the scope of this reaction, a series of substituted dibenzalacetones (1a-p) were reacted with allenoate $\mathbf{2}$ under solvent-free conditions (see Table 1). Catalysts $\mathbf{A}$ and $\mathbf{B}$ (see Scheme 2) were employed to access either enantiomer of the corresponding oxatrienes $\mathbf{3 a - p}$. Overall, catalyst A displayed better efficiency and stereoinduction over catalyst $\mathbf{B}$.

Regardless of the electronics of the substituents attached; i.e., electron-donating aryl (entries 2-6 and 13), electron-withdrawing aryl (entries 7-12), and even aliphatic substituents (entries 14-16), excellent enantioinduction was observed with catalyst A. ${ }^{12}$ The X-ray crystal structures of derivatives of $\mathbf{3 b}-(S)$ and $\mathbf{3 j}-(S)$ provided unequivocal evidence for the absolute stereochemistry of the products obtained using catalyst A (see Scheme 3, dashed box). These results also corroborated the quantum chemical computational analysis (Figure 1a) that revealed the absence of a gauche interaction (sterics) in TS-1 is responsible for favoring the $(S)$-enantiomer.

As a proof of principle, we briefly explored the ability of these oxatrienes to govern regioand stereoinduction in the Diels-Alder reaction. Scheme 3 summarizes the results of 11 cycloaddition reactions of dienes $\mathbf{3 a}-(S), \mathbf{3 b}-(S), \mathbf{3 c}-(S)$, and $\mathbf{3 j}-(S)$ with an illustrative set of dienophiles $\mathbf{4 a - d}$. Dienophiles $\mathbf{4 a}$ and $\mathbf{4 b}$ exhibited exclusive diastereoselective addition, whereas $\mathbf{4 c}$ and $\mathbf{4 d}$ displayed excellent regioselection. Furthermore, these sequential transformations (Baylis-Hillman reaction followed by a concomitant Diels-Alder reaction) were also performed efficiently as a "one-pot" domino reaction (see Scheme 3 for products 5aa and 5ab). As anticipated, the cross-conjugation of the endocyclic oxygen (O1) not only enhances the HOMO energy of the diene motif in 3 but also generates an electronic bias that allows regiospecific trapping of the dienophiles $\mathbf{4 c}$ and $\mathbf{4 d}$, thus validating the initial 
hypothesis. Of interest is the reaction of $\mathbf{3 a}$ with $\mathbf{4 d}$, which led to an isomeric mixture of products 5ad and 6ad in nearly equimolar ratios. Fortuitously, upon treatment with DBU in refluxing DCM, the mixture was cleanly converted to yield the endocyclic product $6 \mathbf{6}$ ad in high diastereo- and regioselectivity. Unlike the products of other Diels-Alder reactions depicted in Scheme 3, 6ad (and for that matter 5ad) is the result of an exo [4 + 2] cycloaddition (see SI for stereochemical assignment based on NMR studies). Although we see no evidence of the endo product during the course of the reaction, we cannot exclude the possibility of either epimerization at C6 or a reversible Diels-Alder process that ultimately settles for the thermodynamic product.

In summary, a two-step process is reported for the synthesis of hexahydro- $2 H$-chromenes. The asymmetric Baylis-Hillman reaction provides the dihydropyrans in high stereoselectivity. The ensuing Diels-Alder reaction is also under strict regio- and stereochemical control. The C4 stereocenter, established during the initial [4 + 2] cycloaddition, is the stereochemical driver, whereas the cross-conjugation of pyranyl oxygen (O1) aids to generate an electronic bias for the observed regioselectivity in the Diels-Alder reaction. This methodology provides a complementary approach to control the stereochemistry in Diels-Alder reactions of chiral dienes: ${ }^{5 \mathrm{~b}, \mathrm{f}, \mathrm{h}, \mathrm{i}}$ unlocking opportunities toward expanding the repertoire of stereo- and regioselective reactions of chiral dienes.

\section{Supplementary Material}

Refer to Web version on PubMed Central for supplementary material.

\section{Acknowledgments}

Generous support was provided by the NIH (GM110525). We are grateful to Dr. Daniel Holmes and Dr. Li Xie (MSU) for assistance on NMR experiments.

\section{References}

1. (a) de Benneville PL, Connor RJ. Am Chem Soc. 1940; 62(283)(b) Griffiths DV, Wilcox G. J Chem Soc Perkin Trans 2. 1988:431.(c) Hanaki N, Ishihara K, Kaino M, Naruse Y, Yamamoto H. Tetrahedron. 1996; 52:7297.(d) Ishihara K, Hanaki N, Yamamoto HJ. Chem Soc Chem Commun. 1995:1117.(e) Jones DN, Khan MA, Mirza SM. Tetrahedron. 1999; 55:9933.

2. (a) Wang X, Fang T, Tong X. Angew Chem Int Ed. 2011; 50:5361.(b) Yang HB, Yuan YC, Wei Y, Shi M. Chem Commun. 2015; 51(6430)(c) Yao W, Dou X, Lu YJ. Am Chem Soc. 2015; 137(54)(d) Zhang S, Luo YC, Hu XQ, Wang ZY, Liang YM, Xu PF. J Org Chem. 2015; 80(7288)(e) Ashtekar KD, Staples RJ, Borhan B. Org Lett. 2011; 13:5732. [PubMed: 21970616]

3. (a) Huang GT, Lankau T, Yu CH. J Org Chem. 2014; 79:1700. [PubMed: 24437625] (b) Evans CA, Miller SJ. J Am Chem Soc. 2003; 125:12394. [PubMed: 14531667]

4. The sequence of events highlighted in path $\mathrm{B}$ is akin to the Baylis- Hillman reaction (thus referred to as the modified $\mathrm{BH}$ ) that has been interrupted with an intramolecular cyclization, prior to the elimination of the amine catalyst, which regenerates the olefin

5. (a) Agopcan S, Celebi-Olcum N, Ucisik MN, Sanyal A, Aviyente V. Org Biomol Chem. 2011; 9(8079)(b) Atta-ur-Rahman, Shah, Z. Stereoselective Synthesis in Organic Chemistry. 1st. SpringerVerlag; New York: 1993. (c) Fisher MJ, Hehre WJ, Kahn SD, Overman LE. J Am Chem Soc. 1988; 110(4625)(d) Galley G, Patzel M. J Chem Soc Perkin Trans. 1996; 1:2297.(e) Gleiter R, Paquette LA. Acc Chem Res. 1983; 16(328)(f) Hamada T, Sato H, Hikota M, Yonemitsu O. Tetrahedron Lett. 1989; 30:6405.(g) Nicolaou KC, Snyder SA, Montagnon T, Vassilikogiannakis G. Angew Chem Int 
Ed. 2002; 41:1668.(h) Siegel C, Thornton ER. Tetrahedron Lett. 1988; 29:5225.(i) Tripathy R, Carroll PJ, Thornton ER. J Am Chem Soc. 1990; 112:6743.

6. (a) Giuliano RM, Jordan AD, Gauthier AD, Hoogsteen KJ. Org Chem. 1993; 58:4979.(b) Jin Z, Yang R, Du Y, Tiwari B, Ganguly R, Chi YR. Org Lett. 2012; 14(3226)(c) Kirillov NF, Gavrilov AG, Slepukhin PA, Vakhrin MI. Russ J Org Chem. 2013; 49:717.

7. (a) Hehre WJ, Ditchfield R, Pople JA. J Chem Phys. 1972; 56:2257.(b) Hariharan PC, Pople JA. Theor Chim Acta. 1973; 28:213.(c) Becke AD. J Chem Phys. 1993; 98(5648)(d) Becke AD. J Chem Phys. 1993; 98(1372)(e) Raghavachari K. Theor Chem Acc. 2000; 103:361.

8. Corey EJ. Angew Chem Int Ed. 2002; 41:1650.

9. (a) Lewars, EG. Computational Chemistry: Introduction to theTheory and Applications of Molecular and Quantum Mechanics. 2nd. Springer-Verlag; New York: 2011. p. 1(b) Wise KE, Wheeler RA. J Phys Chem A. 1999; 103:8279.

10. An exhaustive analysis at the MP2 level of theory can be attempted (requires longer time and higher computational expense) to capture the precise energetics in the Diels-Alder reaction, however, our approach utilizes the B3LYP/6-31G*analysis to map the reaction pathway and compare the relative energies of the transition states involved at a relatively low computational expense

11. The final ESI-MS spectrum displayed the same peaks regardless of the order of addition of $\mathbf{1 a}, \mathbf{2}$, and C. MS spectra obtained at longer time points depict the anticipated difference in relative intensities of the intermediates as the reaction progresses to yield more product. Futhermore, for simplicity, Figure 2 depicts adducts that arise only from $\gamma$-attack of the allene ester, whereas the actual mixture may comprise equilibrating intermediates formed via $\gamma$ and $a$ attack

12. We have also explored the Baylis-Hillman reaction with unsymmetrically substituted enones. The resulting products obtained with modest selectivity of 2:3 were inseparable by analytical techniques to evaluate the stereoinduction (see the Supporting Information for details) 
a.

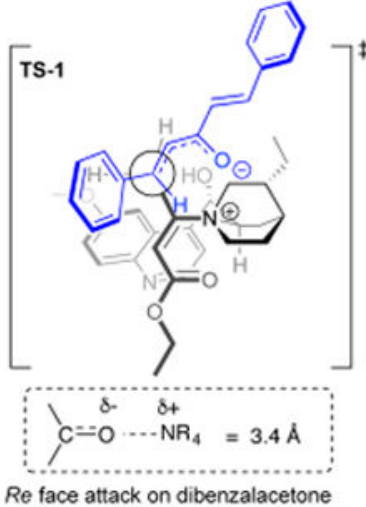
yields the (S)-enantiomer of $3 a$

$$
\Delta \Delta H_{(\text {ref })}=0.0 \mathrm{kcal} / \mathrm{mol}
$$

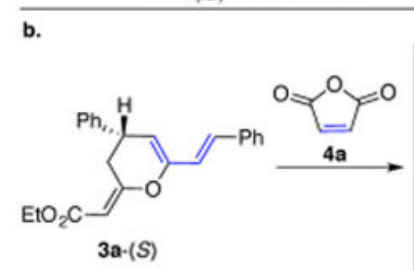

3a-(S)
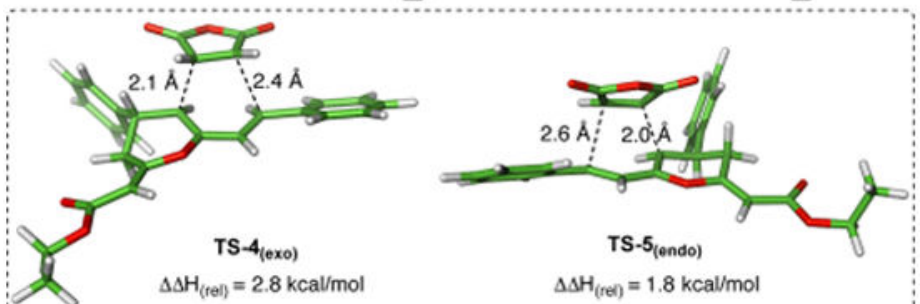

Figure 1.

(a) Two diastereomeric transition states TS-1 and TS-2 calculated at the B3LYP/6-31G*/ SM8(toluene) level of theory. The bonds highlighted in red color depict the unfavorable gauche interactions in TS-2. (b) Three possible transition states associated with the [4+2] cycloaddition of $\mathbf{3 a}-(S)$ and $\mathbf{4 a}$. TS-3 (endo) is favored by $2.8 \mathrm{kcal} / \mathrm{mol}$ over TS-4 (exo) and by $1.8 \mathrm{kcal} / \mathrm{mol}$ over TS-5 (endo). The fourth possible TS involving an exo approach of $4 \mathbf{a}$ from the same face as the $\mathrm{C} 4-\mathrm{Ph}$ substituent cannot be calculated due to severe steric clash between the approach dienophile and the aromatic ring. 
a.
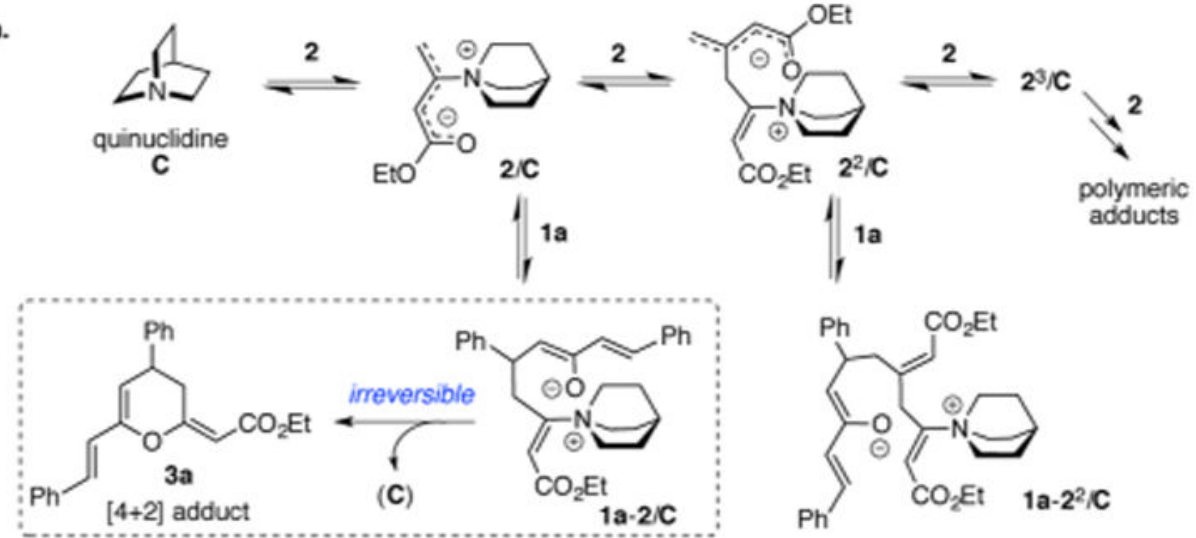

I

adducts

b.

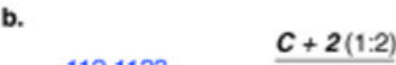

c.

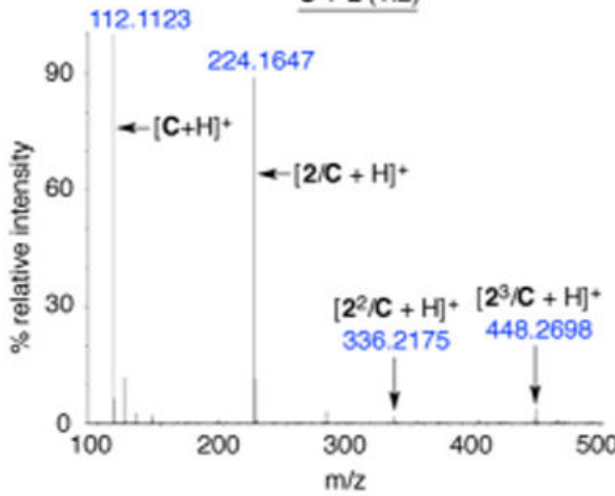

$\underline{C+2+1 a(1: 2: 2)}$
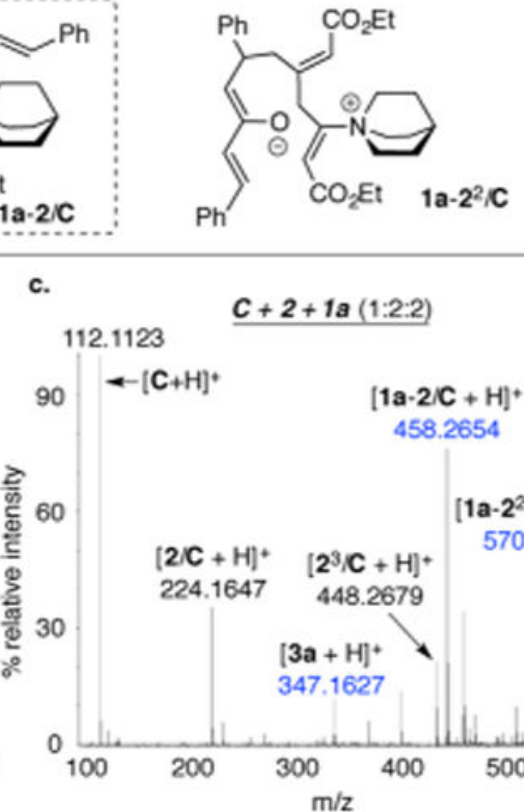

$\mathrm{Ph}$ 

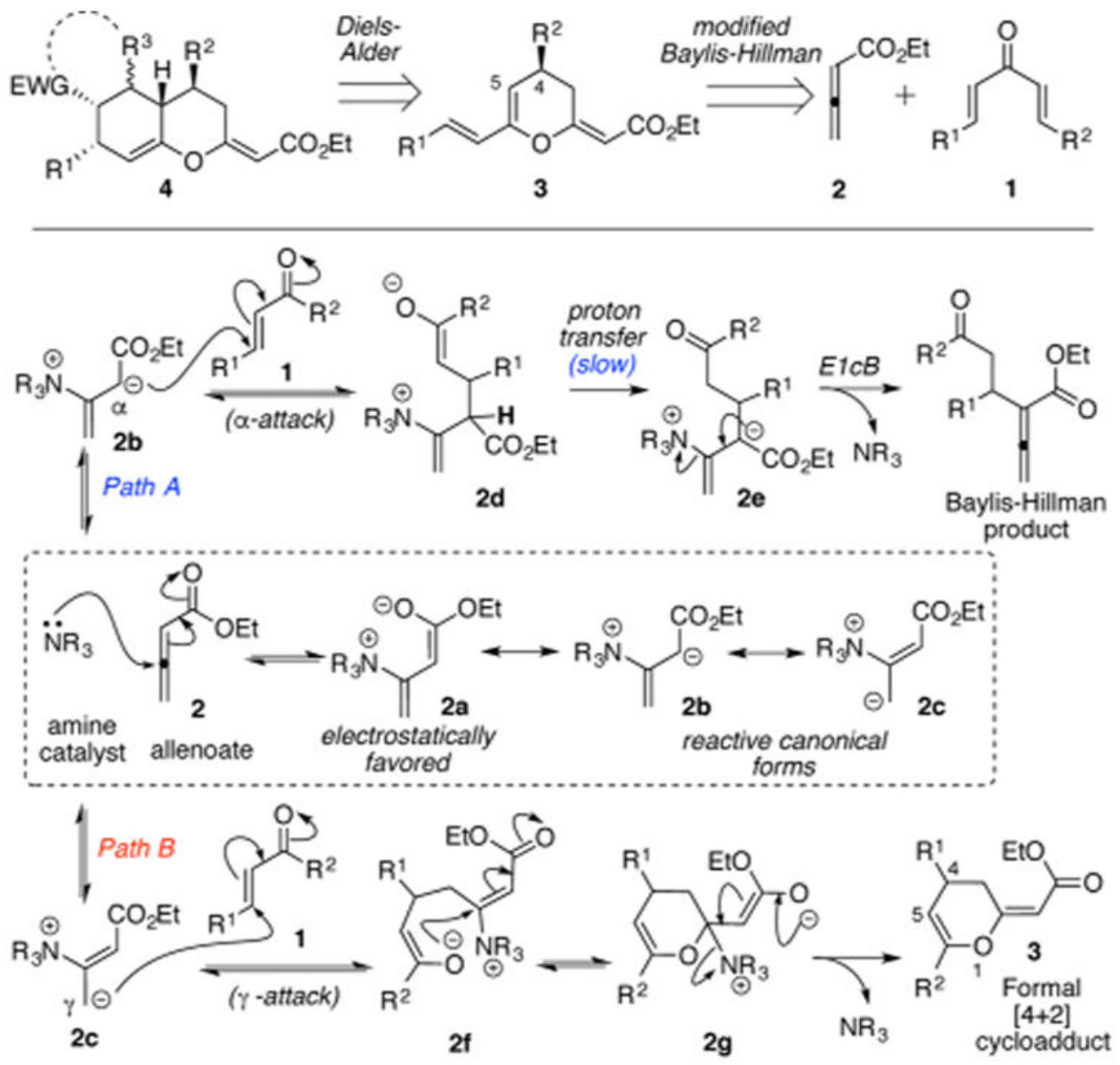

Scheme 1. (Top) Retrosynthetic Strategy for the Synthesis of Hexahydro-2H-chromenes. (Bottom) Paths A and B Represent a Simplified Mechanistic Picture of the Canonical vs the Modified Baylis-Hillman Pathway ${ }^{a}$

${ }^{a}$ Possible resonance structures of the amine-allenoate adduct are shown in the dashed box with $2 \mathbf{a}$ being the major contributor. 

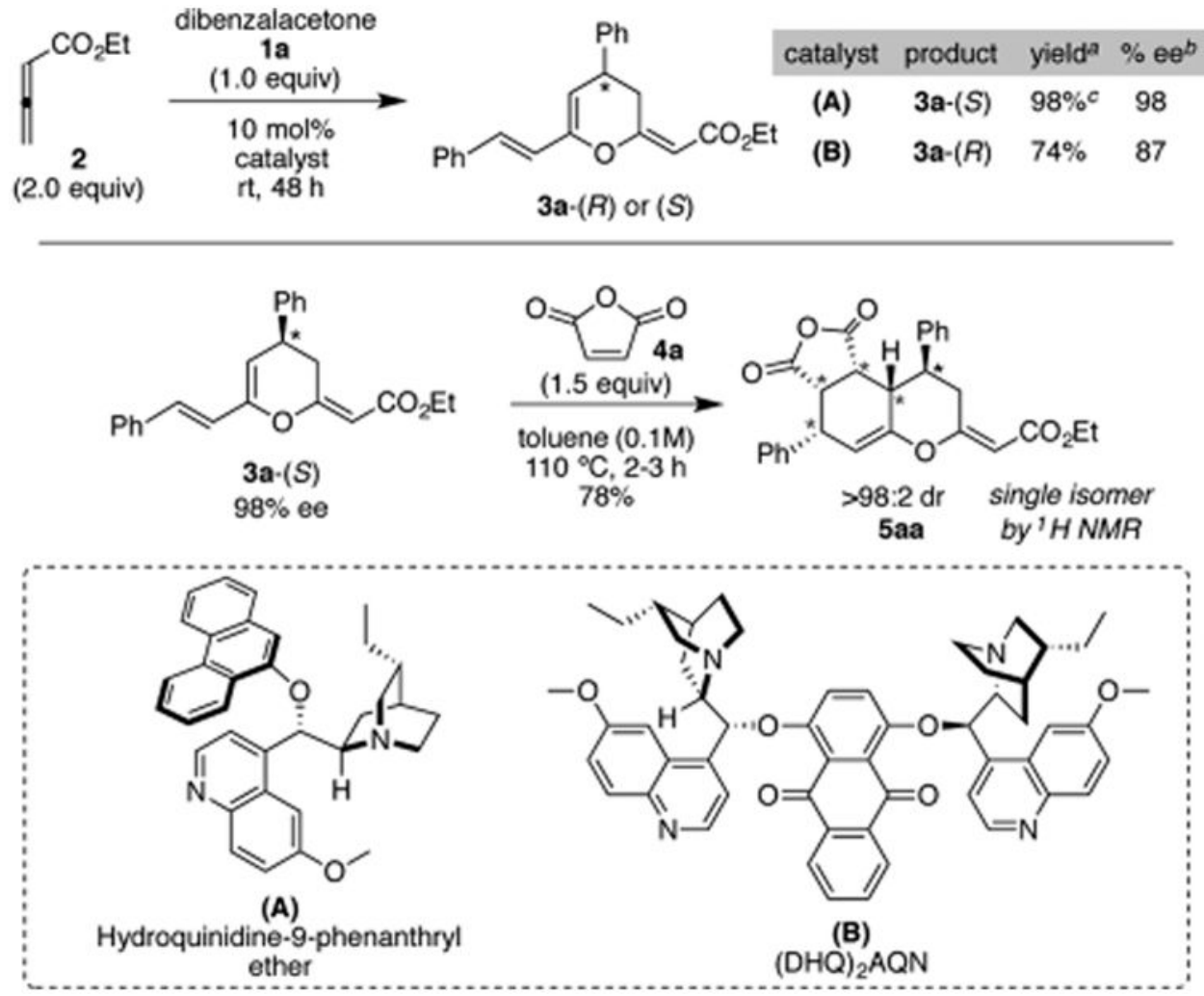

Scheme 2. Preliminary Results for Consecutive [4 + 2] Cycloadditions under Optimized Conditions Using Dibenzalacetone (1a) as a Test Substrate ${ }^{a-c}$

${ }^{a}$ Isolated yields. ${ }^{b}$ Ratios were determined by HPLC analysis. ${ }^{c}$ Reaction was performed using $1 \mathrm{~g}(4.3 \mathrm{mmol})$ of $\mathbf{1 a}$. 

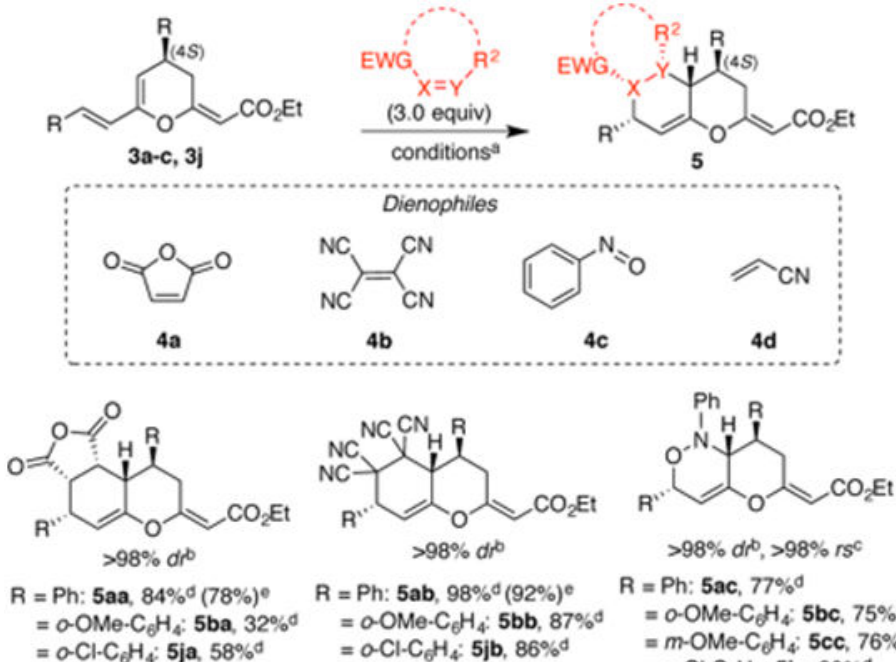

$R=\mathrm{Ph}: 5 \mathrm{ab}, 98 \%{ }^{d}(92 \%)^{\mathrm{e}}$

$\begin{aligned} \mathrm{R} & =\mathrm{Ph}: 5 \mathrm{ac}, 77 \% \mathrm{~d} \\ & =0-\mathrm{OMe} \cdot \mathrm{C}_{6} \mathrm{H}_{4} ; \mathrm{bbc}, 75 \%\end{aligned}$

$=0-\mathrm{OMe}_{6} \cdot \mathrm{C}_{6} \mathrm{H}_{4}: 5 \mathrm{bb}, 87^{\circ}$

$=m-\mathrm{OMe}-\mathrm{C}_{2} \mathrm{H}_{4} ; 5 \mathrm{cc}, 76 \%$ d

$=0-\mathrm{Cl}_{6} \mathrm{C}_{6} \mathrm{H}_{4} \div 5 \mathrm{jc}, 80 \% \mathrm{~d}$
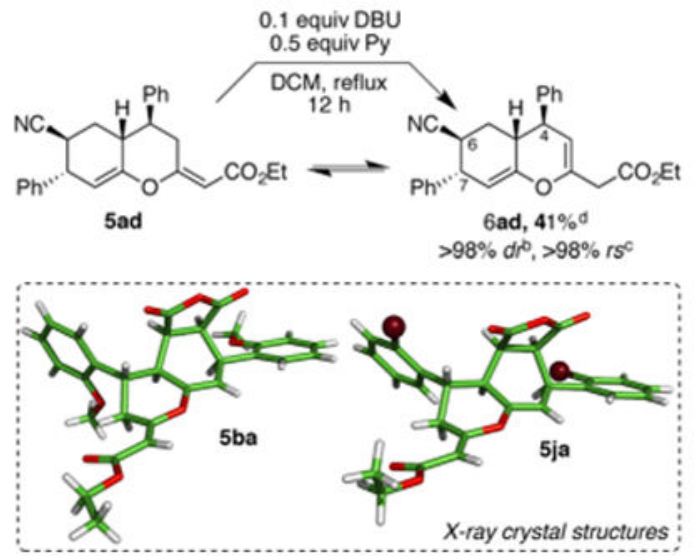

Scheme 3. Diels-Alder Reaction of Substituted Oxatrienes 3a-c,j with Illustrative Dienophiles $4 \mathrm{a}-\mathrm{d}^{a-e}$

${ }^{a}$ Diels-Alder reaction conditions for each dienophile are as follows: dienophile $\mathbf{4 a}, 0.1 \mathrm{M}$ toluene, reflux, 2-16 h; dienophile 4b, 0.1 M toluene, reflux, $2 \mathrm{~h}$; dienophile 4c, $0.1 \mathrm{M}$ EtOH/DCM (1:1), $0{ }^{\circ} \mathrm{C} \rightarrow \mathrm{rt}, 12 \mathrm{~h}$; dienophile 4d, 0.1 $\mathrm{M}$ in toluene, reflux, 12

h. ${ }^{b}$ Diastereomeric ratios (dr) were determined by ${ }^{1} \mathrm{H}$ NMR analysis of the crude reaction mixture. ${ }^{c}$ Regioselectivity (rs) and relative stereochemistry were determined via NMR analysis of the purified product. "Isolated yields. "Isolated yields for "one pot" consecutive transformations from 1a as a starting material.

Org Lett. Author manuscript; available in PMC 2017 March 08. 


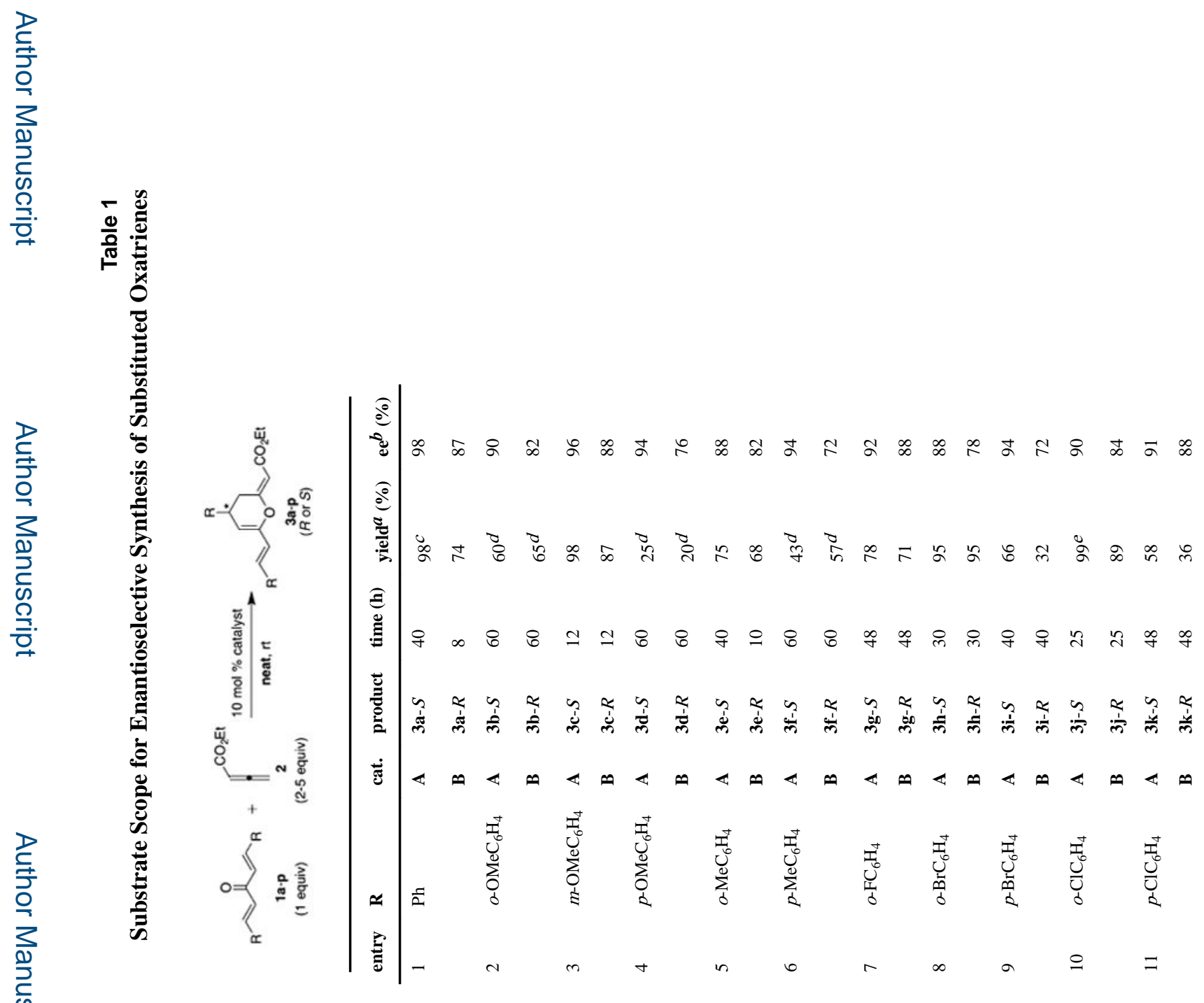



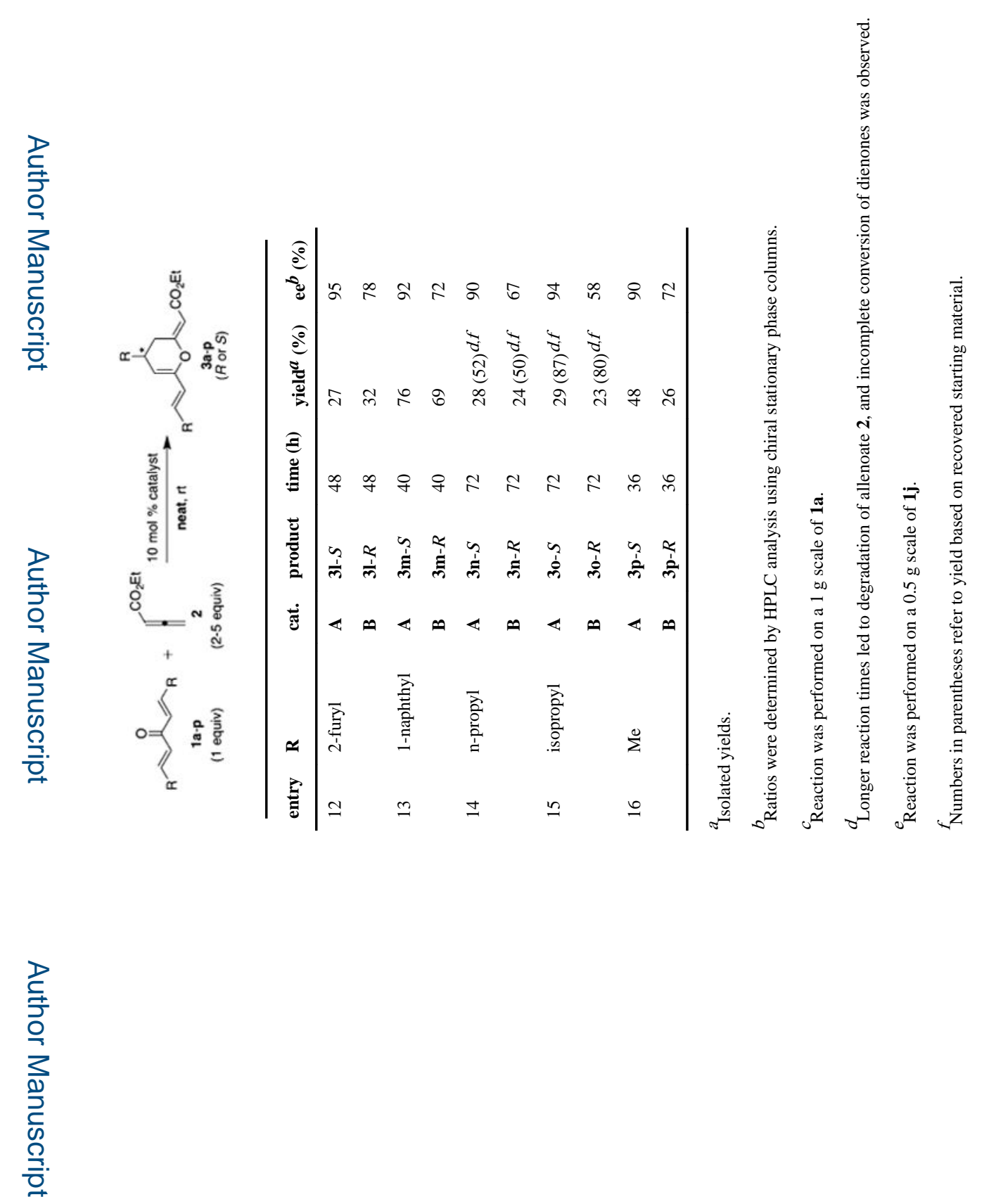

로을

Org Lett. Author manuscript; available in PMC 2017 March 08. 